\title{
The Role of Fibronectin Binding in the Rat Model of Experimental Endocarditis Caused by Streptococcus sanguis
}

\author{
J. H. Lowrance, ${ }^{\star *}$ L. M. Baddour, ${ }^{5}$ and W. A. Simpson*\$il \\ *The H. S. Truman Veterans Administration Hospital and Departments of ${ }^{\S}$ Medicine and "Molecular Microbiology and Immunology, \\ University of Missouri, Columbia, Missouri 65201; and ${ }^{\ddagger}$ Department of Microbiology and Immunology, \\ University of Tennessee, Memphis, Tennessee 38163
}

\begin{abstract}
Inactivation of fibronectin (Fn) binding by insertional mutagenesis of Streptococcus sanguis with Tn916 reduces virulence of this bacterium in the rat model of infective endocarditis (IE). Transconjugants were screened for Fn adherence using an ELISA adherence test. One transconjugant had a decreased adherence to immobilized Fn. Southern hybridization demonstrated that the insertion occurred only once in this mutant. The parent strain and mutant strain JL113 were used as challenge strains in a rat endocarditis model. These experiments demonstrated that the mutant had a reduced ability $(P<0.05)$ to produce IE. Spontaneous excision of Tn916 from JL113 produced strains identical to both the parental and mutant phenotypes. One strain (JLR-19) that retained the mutant phenotype and one (JLR-15) that regained the parental phenotype for Fn binding were tested for their ability to produce IE. These strains demonstrated that the ability to bind Fn and to produce IE were correlated after Tn916 excision. The reduced virulence of the mutant suggested that adherence of $S$. sanguis to immobilized Fn plays an important role in the production of IE. (J. Clin. Invest. 1990. 86:7-13.) Key words: endocarditis • fibronectin $\bullet$ adherence $\bullet S$. sanguis
\end{abstract}

\section{Introduction}

Streptococcus sanguis is a leading cause of both native valve and late-onset prosthetic valve endocarditis (1-3). Recent reviews suggest that bacterial adherence to certain blood components or extracellular matrix proteins leads to the adherence and colonization of bacteria to damaged valvular surfaces (4, 5). These blood components include laminin, collagen, platelets, and fibronectin (Fn) ${ }^{1}(6-9)$. Fn is found in plasma as a soluble form and in tissue as a bound, immobilized form. We have found previously that $S$. sanguis binds to a conformationally specific domain on the immobilized Fn molecule that is not exposed by soluble Fn (7). These studies suggested that $S$. sanguis could bind to Fn immobilized at sites of tissue damage in the blood stream, and Fn therefore could act as a tissue receptor for this bacterium. To test this hypothesis we constructed a mutant that was defective in Fn binding. In this

Address reprint requests to Dr. W. A. Simpson, H. S. Truman Memorial Veterans Hospital, 800 Hospital Drive, Columbia, MO 65201

Received for publication 14 September 1989 and in revised form 21 February 1990

1. Abbreviations used in this paper: Fn, fibronectin; IE, infective endocarditis; SBA, sheep blood agar, Sm, streptomycin; Tc, tetracycline.

The Journal of Clinical Investigation, Inc.

Volume 86, July 1990, 7-13 study we show that this mutant was less virulent in the rat model of infective endocarditis (IE) than the parent strain that bound Fn. This suggests a correlation between Fn binding in the in vitro assays and the ability of $S$. sanguis to adhere to damaged tissues and produce IE in the animal model.

\section{Methods}

Bacteria. All streptococcal strains were grown in Todd-Hewitt broth (Difco Laboratories Inc., Detroit, MI) for $18 \mathrm{~h}$ at $37^{\circ} \mathrm{C}$. Strains were stored at $-70^{\circ} \mathrm{C}$ until needed. Tetracycline (Tc) and streptomycin (Sm) were added to media as required at concentrations of 5 and 500 $\mu \mathrm{g} / \mathrm{ml}$, respectively. Enterococcus faecalis $\mathrm{CG} 110$, which contains the conjugative transposon Tn916, and Escherichia coli CG120, which harbors the plasmid pAM120 that contains Tn916, were gifts from D. B. Clewell (University of Michigan, Ann Arbor, MI). S. sanguis Challis was obtained from R. J. Doyle (University of Louisville, Louisville, KY) and was the primary organism used in this study (10). This streptococcal strain does not harbor detectable plasmids and causes experimental IE in rats. All Tn916 insertional mutants were derived from a naturally occurring $\mathrm{Sm}$-resistant mutant of $S$. sanguis Challis, identified as 1C261. See Table I for a list of strains used in these studies.

Adherence assays. Bacteria were harvested by centrifugation, washed twice, and suspended in $\mathrm{PBS}\left(0.02 \mathrm{M} \mathrm{PO}_{4}\right.$ and $0.15 \mathrm{M} \mathrm{NaCl}$, $\mathrm{pH}$ 7.4). Suspensions were adjusted to the indicated optical density values $(530 \mathrm{~nm})$ with a Coleman Junior II spectrophotometer (PerkinElmer, Oak Brook, IL). Adherence assays were carried out on microtiter assay plates as previously described (7).

Mutagenesis. S. sanguis mutants were derived from matings with $E$. faecalis CG110, which harbors the conjugative transposon Tn916 $(10,11)$. Matings were carried out by mixing the recipients and donors in a 10:1 ratio and plating a heavy slurry of this mixture on ToddHewitt agar containing 5\% sheep blood agar (SBA) at $37^{\circ} \mathrm{C}$ overnight. Cells were collected from the agar surface with sterile swabs and then suspended in $1 \mathrm{ml}$ of PBS. Serial dilutions were plated on SBA containing the appropriate selective antibiotics. Transfer frequencies were obtained by dividing the number of transconjugants by the number of viable recipients. The average transposition frequency was $10^{-7}$.

Preparation of $F n$. Human plasma Fn was purified by affinity chromatography according to the method of Engvall and Ruoslahti (12) as previously described $(13,14)$. Gelatin was obtained commercially (Fisher Scientific Co., Pittsburgh, PA).

Preparation of antisera. Antisera directed against $S$. sanguis were prepared by subcutaneous injection of New Zealand white rabbits in the back of the neck with an inoculum of $0.5 \mathrm{ml}$ of $1 \times 10^{8} \mathrm{CFU} / \mathrm{ml}$ in PBS emulsified in Freund's complete adjuvant. Two subsequent booster injections were given intravenously at 2-wk intervals with the same number of bacteria in sterile PBS. Antisera were collected, assayed for antibody titer, and stored at $4^{\circ} \mathrm{C}$ until needed.

Screen for $S$. sanguis with defective adherence to immobilized Fn. Adherence assays were performed as previously reported (7). Briefly, gelatin was immobilized onto microtiter plates (F16, high-binding, microwell module; Nunc, Roskilde, Denmark) by adding $200 \mu \mathrm{l}$ of the protein solution $(50 \mu \mathrm{g} / \mathrm{ml}$ in $0.05 \mathrm{M}$ sodium carbonate buffer, $\mathrm{pH} 9.6)$ to each well and incubating the plates for $16 \mathrm{~h}$ at $4^{\circ} \mathrm{C}$. Plates were 
Table I. Strains of Bacteria Used in This Study

\begin{tabular}{lll}
\hline \multicolumn{1}{c}{ Strain and species } & \multicolumn{1}{c}{ Characteristics } & \multicolumn{1}{c}{ Source } \\
\hline CG110 E. faecalis & Tn916 donor & D. B. Clewell, University of Michigan \\
Challis S. sanguis & Streptomycin sensitive & R. Doyle, University of Louisville \\
1C261 $S$. sanguis & Streptomycin resistant Challis & This study \\
JL113 $S$. sanguis & Tn916 mutant of 1 C261 that doesn't bind to Fn & This study \\
JL21 1 S. sanguis & Random Tn916 insertion of 1 C261 that binds to Fn & This study \\
JLR-15 S. sanguis & JL113 with Tn916 excised (regained Fn binding) & This study \\
JLR-19 S. sanguis & JL113 with Tn916 excised (retained JL113 phenotype) & This study
\end{tabular}

washed three times with PBS before use (all subsequent washes were the same). Transconjugants were grown overnight at $37^{\circ} \mathrm{C}$ in $1 \mathrm{ml}$ microfuge tubes and harvested by centrifugation for $10 \mathrm{~min}$ at 8,000 rpm in a Beckman-12 microfuge (Beckman Instruments, Inc., Palo Alto, CA). Each bacterial pellet was resuspended in $0.5 \mathrm{ml}$ of PBS and $50 \mu$ of this suspension was then added to an equal volume of PBS containing Fn $(100 \mu \mathrm{g} / \mathrm{ml})$. The bacterial-Fn mixtures were applied to the assay plates $(100 \mu \mathrm{l} /$ well). Microtiter plates were incubated at room temperature for $\mathbf{3 0}$ min with circular shaking. Nonadherent bacteria were removed with several washes of PBS. Adherent bacteria were fixed to the plates with a $15-\mathrm{min}$ incubation at $60^{\circ} \mathrm{C}$. After cooling to room temperature, a 1:200 dilution of antisera against $S$. sanguis (in PBS with 5\% BSA) was added to each well and incubated for $1 \mathrm{~h}$ at $37^{\circ} \mathrm{C}$. Plates were washed with PBS and a 1:1,000 dilution (in PBS with 5\% BSA) of peroxidase-labeled goat anti-rabbit IgG (Cooper Biomedical Inc., Malvern, PA) was applied and incubated for $1 \mathrm{~h}$ at $37^{\circ} \mathrm{C}$. $O$-Phenylenediamine was used as the chromophore and the color was allowed to develop for $30 \mathrm{~min}$, after which the $\mathrm{A}_{450}$ was measured with a MicroELISA reader (Dynatech Corp., Alexandria, VA).

Cultures of transconjugants that were identified as nonadherent were reassayed on three separate occasions. The stability of the nonadherent phenotype was then verified by plating each culture and performing independent adherence experiments on 20 colonies of each presumed mutant. In addition, since the anti-S. sanguis antibody used in this assay was directed against the parent, a particle ELISA was conducted to determine that the antibody activity against the selected transconjugants, mutant, and parent were the same (15). These tests verified that reactivities were the same for all organisms used in this study. Initial studies showed that the absorbance values measured were directly related to the number of adherent bacteria. The absorbance increased proportionately when the concentration of bacterial suspensions increased from an optical density of 0.1 to $0.4(530 \mathrm{~nm})$ and then became saturated at higher bacterial concentrations. Controls in each assay included the parent $S$. sanguis and $E$. faecalis CG110 strains.

Production of experimental endocarditis. The technique used to produce experimental endocarditis in rats was adapted from Santoro and Levison and has been previously used in our laboratory $(16,17)$. Briefly, a polyethylene catheter (Intramedic PE10; Clay Adams, Parsippany, NJ) was inserted into the left ventricular lumen via the right common carotid artery and secured. $48 \mathrm{~h}$ later the animals were challenged by intravenous injection. The rats were killed $4 \mathrm{~d}$ later and the hearts and indwelling catheters were resected for microbiologic analysis. No antibiotics were administered during the course of catheter insertion or after the challenge of bacteria.

Vegetations from each animal were pooled, weighed (wet), and homogenized with a sterilized mortar and pestle in $1 \mathrm{ml}$ of PBS. After homogenization, the vegetation suspension was diluted in PBS and plated onto SBA for quantitative colony counts. The remaining portion of the suspension that was not used in the quantitation procedure was cultured in Todd-Hewitt broth overnight at $37^{\circ} \mathrm{C}$.

Indwelling catheters were resected and placed into tubes containing Todd-Hewitt broth overnight at $37^{\circ} \mathrm{C}$ for qualitative cultures. No quantitative cultures of the catheters were performed.
Chromosomal DNA isolation. Chromosomal DNA from $S$. sanguis was prepared from overnight cultures. The cells were pelleted by centrifugation for $10 \mathrm{~min}$ at $12,000 \mathrm{~g}$, after which the cells were washed twice with PBS. The final pellet was resuspended in $5 \mathrm{ml}$ of TE $(10 \mathrm{mM}$ Tris, pH 8.0, and $1 \mathrm{mM}$ EDTA). To this solution, 1,000 $\mathrm{U}$ of mutanolysin (Sigma Chemical Co., St. Louis, MO) was added and incubated for $2-3 \mathrm{~h}$ in a $55^{\circ} \mathrm{C}$ water bath. After this incubation was complete 0.5 $\mathrm{ml}$ of $10 \%$ SDS was added with gentle mixing. The mixture was then incubated for $10 \mathrm{~min}$ in a $55^{\circ} \mathrm{C}$ water bath or until lysis was complete. DNA was extracted with phenol and chloroform according to the method of Maniatis et al. (18). The DNA was then precipitated with ethanol and resuspended in TE buffer.

Plasmid pAM120, the probe for Tn916, and the chromosomal DNAs were digested with Hind III as recommended by the manufacturer.

Hybridization. DNA hybridizations were performed by the method of Southern (19) with the modifications of Wahl et al. (20). Briefly, hybridizations with the labeled probes were carried out in $50 \%$ formamide for $20 \mathrm{~h}$ at $42^{\circ} \mathrm{C}$. Filters were then washed once in $2 \times \operatorname{SSC}(1 \times$ $\mathrm{SSC}$ is $0.15 \mathrm{M} \mathrm{NaCl}, 0.015 \mathrm{M} \mathrm{Na}$ citrate, $\mathrm{pH} \mathrm{7.4)}$ ) containing $0.1 \%$ SDS at room temperature, twice in $6 \times \mathrm{SSC}, 0.1 \% \mathrm{SDS}$ at $65^{\circ} \mathrm{C}$ for $30 \mathrm{~min}$ each, and once in $2 \times \mathrm{SSC}, 0.1 \% \mathrm{SDS}$ at $65^{\circ} \mathrm{C}$ for $15 \mathrm{~min}$. Probes were nick translated with $\left.{ }^{32} \mathrm{P}\right] \mathrm{dCTP}$ using a nick translation kit (Bethesda Research Laboratories, Gaithersburg, MD) and following the manufacturer's instructions. Filters were dried and used to expose a sheet of $\mathrm{X}-$ Omat R film (Eastman Kodak Co., Rochester, NY) at $-70^{\circ} \mathrm{C}$. Typically, an exposure of 24-36 h was sufficient to see the labeled bands.

Electron microscopy. Samples of bacteria to be examined for the presence of fibrillar structures were applied to Forvar-coated copper grids and negatively stained with $0.5 \%$ phosphotungstic acid (pH 4.0). Bacteria to be examined for exopolysaccharides were fixed in 5\% glutaraldehyde in $0.1 \mathrm{mM}$ cacodylate buffer containing $0.15 \%$ ruthenium red (pH 7.0) for $2 \mathrm{~h}$ at $20^{\circ} \mathrm{C}$. Specimens were washed five times in buffer containing $0.5 \%$ ruthenium red, fixed for $2 \mathrm{~h}$ at $20^{\circ} \mathrm{C}$ in $2 \%$ $\mathrm{OsO}_{4}$, and washed several times in the cacodylate buffer. Washed specimens were dehydrated through a graded series of acetone, embedded in Vestopal W, and sectioned. Electron micrographs were made using an EM6B electron microscope (AEI Scientific Instruments, Inc., Elmsford, NY)

Twitching. Bacteria to be examined for twitching or spreading were inoculated on Todd-Hewitt agar containing 5\% sheep blood so as to obtain single colonies (21). Plates were incubated at $35^{\circ} \mathrm{C}$ for $5 \mathrm{~d}$ in a closed, humid container. Plates were then examined for the presence of spreading colonies using a dissecting microscope.

Biochemical and growth characterization of bacterial isolates. A series of biochemical tests were performed to confirm the identity of the parent and mutant phenotypes used in this study. The classification scheme of Facklam was used for the differentiation of viridans streptococci in conjunction with biochemical tests and growth characteristics (22).

Briefly, bacteria were tested for hydrolysis of arginine and esculin, the production of acid from inulin, lactose, sucrose, raffinose, and trehalose, and growth tolerance to $6.5 \% \mathrm{NaCl}$ and $0.1 \%$ tetrazolium 
medium. In addition, colonial morphology and hemolytic characteristics were determined after overnight growth on 5\% SBA. Extracellular polysaccharide production was tested by growing the bacteria on Todd-Hewitt agar supplemented with $5 \%$ sucrose and in Todd-Hewitt broth supplemented with $5 \%$ sucrose.

Growth characteristics were performed by inoculating each organism into Todd-Hewitt broth at $10^{8} \mathrm{CFU} / \mathrm{ml}$. Plate counts were done to determine the number of viable bacteria per milliliter in each dilution. Optical density values of a 1:10 dilution of each organism were taken at $530 \mathrm{~nm}$ on a Junior II spectrophotometer (Coleman) over a period of several hours until the stationary phase was reached. Growth curves were plotted according to absorbance or viable bacteria versus time.

Statistical evaluation. Differences between the proportion of animals infected by different challenge inocula were analyzed by the $\chi^{2}$ test. Differences in mean vegetation weights and mean vegetation bacterial concentrations were evaluated by use of the $t$ test for unpaired data.

\section{Results}

Insertional mutagenesis of Streptococcus sanguis with Tn196. In three separate mating experiments we found that CG110 transferred Tc resistance to strain $1 \mathrm{C} 261$ at a frequency of 1 per $10^{7}$ live recipients. This frequency was 1,000 -fold higher than that found for naturally occurring $T c$ resistance when this strain was tested in control experiments. 5,000 colonies were selected from these mating experiments and tested for their ability to bind to immobilized Fn. Screening of these colonies produced one strain (JL113) that consistently exhibited reduced adherence to Fn. In adherence tests, JL113, the mutant strain, adhered less to immobilized Fn than did the parent strain, 1C261 (Fig. 1). Even with increasing bacterial concentration, JL113 adhered less than 1C261. The control strain, JL211, a transconjugant, was randomly picked from the mating experiments and exhibited equivalent binding to immobilized Fn as did the parent strain (Fig. 2). These results indicate that random insertion of Tn916 and/or growth in Tc-containing media are not responsible for the observed decrease in Fn binding ability by the mutant strain JL113. Therefore, the reduced binding was specific for the site of $T n 916$ insertion.

Morphological, biochemical, and growth characterization of $1 C 261$ and JL113. The phenotypes of the parent, 1C261, and the mutant, JL113, were compared for differences in morphological, biochemical, and growth characteristics. These measurements were conducted to determine if major differences existed between these two phenotypes other than their ability to bind to immobilized Fn. If the insertion of $T n 916$ has

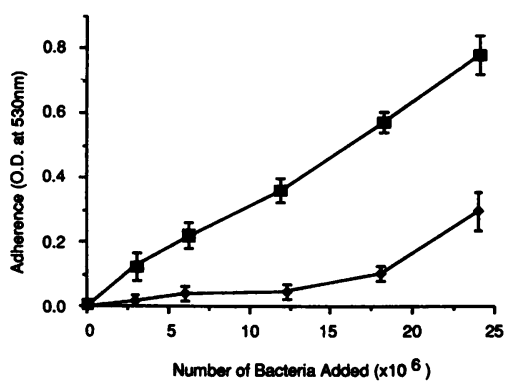

Figure 1. Comparison of $1 \mathrm{C} 261$ and $\mathrm{JL} 113$ adherence to immobilized Fn. Bacteria were allowed to adhere to gelatin-coated microdilution wells $(50 \mu \mathrm{g} / \mathrm{ml})$ in the presences of $\mathrm{Fn}$ $(50 \mu \mathrm{g} / \mathrm{ml})$. Strain $1 C 261$ (ø) adherence to Fn increased signifcantly $(P<0.05)$ with

increasing numbers of bacteria as compared with JL113( 1$)$. The number of bacteria added to the microtiter plates was determined by viable plate counts. The vertical lines at each point indicate SEM ( $n$ =4).

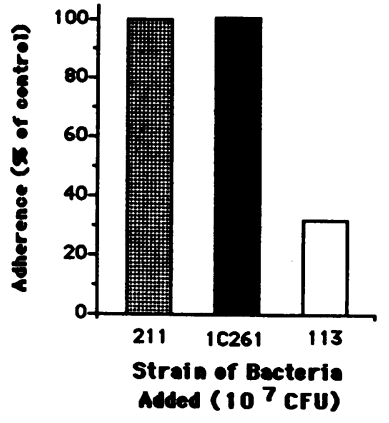

Figure 2. Comparison of the adherence for the transconjugant JL211, the parent 1C261, and the mutant JL113 to immobilized Fn. Bacteria were washed and adjusted to an $\mathrm{A}_{530}$ of 0.4. The bacteria were added to microtiter wells (100 $\mu \mathrm{l} / \mathrm{well})$. The adherence of JL211 and 1C261 are significantly different from JL113 $(P$ $<0.001$ ).

affected the Fn-binding ability of JL113, the same insertion may also affect other processes, which in turn may affect the virulence of JL113.

When JL113 and 1C261 were grown on 5\% SBA, they formed alpha-hemolytic, pinpoint, round colonies. Neither phenotype would grow on $6.5 \% \mathrm{NaCl}$ agar or $0.1 \%$ tetrazolium media. Using electron microscopy, both JL1 13 and 1C261 had a similar appearance when examined for extracellular polysaccharides by ruthenium red staining and for fibrillar structures by negative staining. The production of extracellular polysaccharides was further demonstrated by growing both phenotypes on 5\% sucrose agar and broth. In each case, JL1 13 and 1C261 produced extracellular polysaccharides. The presence of fibrillar structures on both phenotypes was further evident by the demonstration of the twitching phenomenon when each phenotype was grown under high humidity for several days.

Each phenotype was tested for a series of biochemical reactions that are outlined by Facklam and are used to differentiate viridans species (22). JL113 and 1C261 both produced acid when grown on sucrose, lactose, trehalose, and inulin. Neither phenotype, however, produced acid from mannitol or raffinose media. Both phenotypes hydrolyzed arginine and esculin. Finally, both phenotypes serologically reacted with group $\mathrm{H}$ antisera. Using these morphological and biochemical characteristics, both phenotypes were identified as $S$. sanguis type I.

Growth curves were performed on both JL113 and 1C261 to determine if a difference existed in their growth rates. In general, both had similar growth curves; however, JL113 reached early stationary phase slightly faster than $1 \mathrm{C} 261$. Both phenotypes had a lag phase of $1 \mathrm{~h}$. Each reached mid-exponential phase by $3.5 \mathrm{~h}$, with a viable cell count of $4.3 \times 10^{9} \mathrm{CFU} /$ $\mathrm{ml}$ for $1 \mathrm{C} 261$ and $1.7 \times 10^{9} \mathrm{CFU} / \mathrm{ml}$ for JL113. Finally, JL113 reached early stationary phase by $4.7 \mathrm{~h}$, with a viable cell count of $2 \times 10^{9} \mathrm{CFU} / \mathrm{ml}$, and $1 \mathrm{C} 261$ reached early stationary phase at $5.25 \mathrm{~h}$, with a viable cell count of $6.4 \times 10^{9} \mathrm{CFU} / \mathrm{ml}$. These data suggest that JL113 and $1 \mathrm{C} 261$ are the same in the 19 morphological and biochemical characteristics measured. These measurements suggest that the insertion of Tn916 in JL113 may not affect a global regulatory gene and may be limited to affecting the Fn-binding ability of this phenotype. Although these tests are limited, further work will better define the insertion site of $\mathrm{Tn} 916$ and the genes affected by its insertion.

Southern hybridization of JL113 DNA. Fig. 3 shows the patterns obtained when Hind III-digested chromosomal preparations of the strains used in these studies were probed with pAM120. Since the transposon Tn916 contains one Hind III 


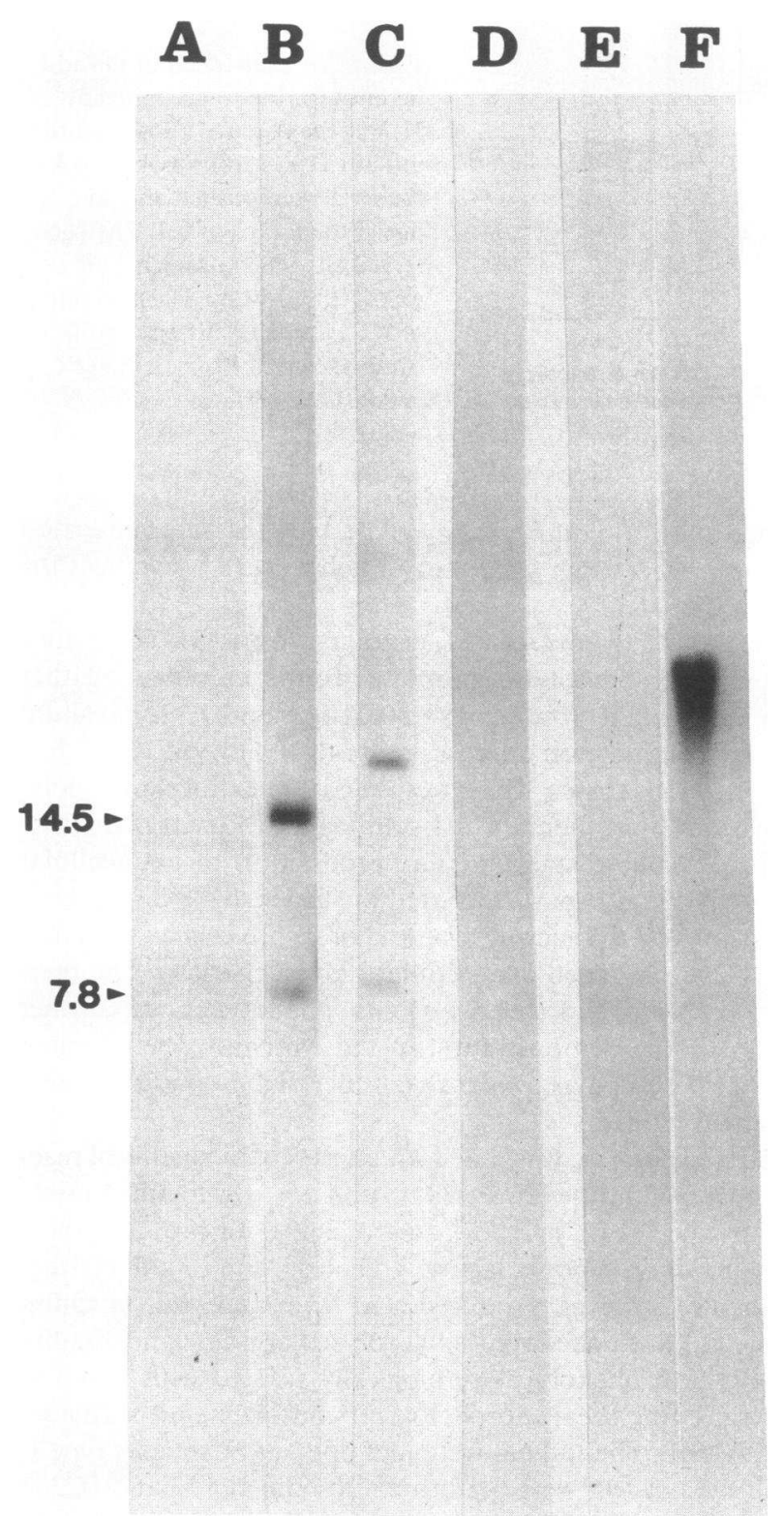

Figure 3. Autoradiogram obtained after Southern transfer of Hind III-digested chromosomal DNA after hybridization with ${ }^{32} \mathrm{P}$-labeled Tn916 probe DNA. Lanes $A-E$ contain DNA (1-1.5 $\mu \mathrm{g})$ from 1C261, JL113, JL211, JLR-15, and JLR-19, respectively. Arrows denote the two junction fragments at JL113 and Tn916. Lane $F$ contains DNA of the pAM120 probe.

site, a single insertion should produce two fragments that hybridize with pAM120 $(10,11)$. Lane $B$ shows the pattern obtained from JL113. Two fragments with apparent sizes of 7.8 and 14.5 hybridize strongly to pAM120. These results suggest that Tn916 is inserting randomly into the chromosome of $S$. sanguis Challis and show that the randomly selected control strain, JL21 1 (lane $C$ ), has inserts at sites different from JL113. No bands that hybridized with 1C261 (lane $A$ ) could be detected in this experiment. To determine whether JL113 contained a single Tn916 insertion as suggested by Fig. 3, lane $B$, further hybridizations were carried out with JL113 DNA that had been digested with Eco RI and Sst I (data not shown). In each case, the hybridizations showed the number of bands predicted from published restriction maps of $\mathrm{Tn} 916$, indicating a single insert $(10,11)$.

Endocarditis studies with the rat model. Once the in vitro Fn-binding properties of $1 \mathrm{C} 261$ and JL113 were established, these strains were examined in an animal endocarditis model. Animals were challenged with three different inocula at $10^{5}$, $10^{6}$, and $10^{7} \mathrm{CFU} / \mathrm{ml}$. Bacterial virulence was monitored by four parameters: vegetation infection rate, vegetation weight, number of organisms per vegetation, and catheter infection rate. All animals challenged with $1 \mathrm{C} 261$ had infection rates of $90 \%$ or greater for the resected vegetations (Fig. 4). Even at the lowest inoculum of $10^{5} \mathrm{CFU}$, the infection rate was $92 \%$ for $1 C 261$. In contrast, the mutant strain, JL113, had a $20 \%$ infection rate when challenged at the highest concentration. None of the animals injected with JL113 were infected at lower inocula ( $10^{5}$ and $\left.10^{6} \mathrm{CFU}\right)$.

Differences were also observed in the virulence of the parental and mutant strains as measured by vegetation weights. Rats injected with $1 \mathrm{C} 261$ had significantly larger vegetations $(P<0.001)$ than did JL113 at all three inocula (Fig. 4). Moreover, the number of viable bacteria per vegetation was significantly greater $(P<0.001)$ for $1 \mathrm{C} 261$ as compared with $\mathrm{JL} 113$ at all three challenge inocula (Fig. 4). These data indicate that JL113 has lost an important virulence factor.

Positive vegetation cultures from rats infected with JL113 were examined to determine if the transposon was in its original location within the chromosome. Attempts to isolate organisms were difficult due to the low infectivity rate of JL113 and the very low numbers of bacteria that could be recovered from the vegetations (Fig. 4). To overcome this problem, a series of three rats were challenged with JL113 at an inoculum of $10^{8} \mathrm{CFU} / \mathrm{ml}$. Only one rat developed IE that cultured positive for JL113, and two isolates from the vegetation were ex-

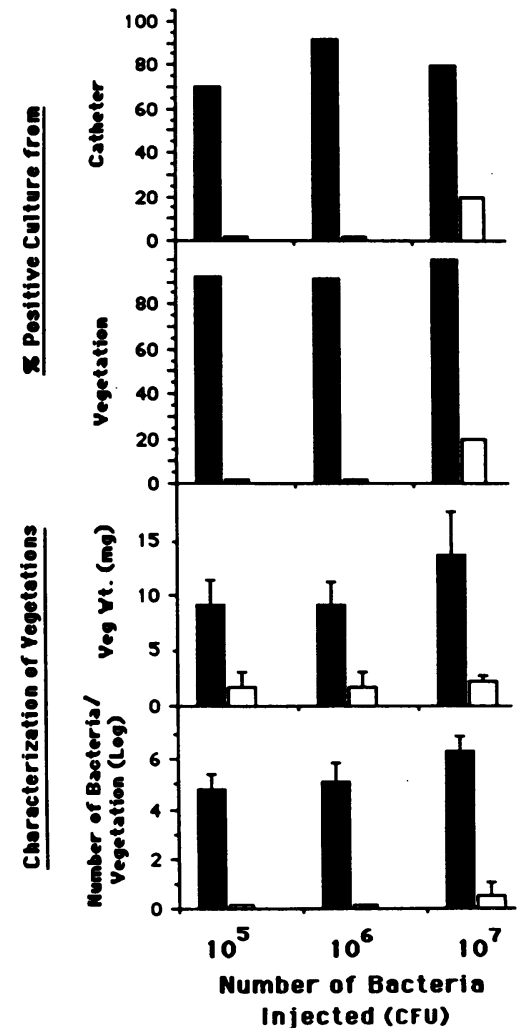

Figure 4. Comparison of $1 \mathrm{C} 261$ and JL113 virulence in the animal model of endocarditis at three different inocula. The parameters of virulence comparisons include infection rates of resected catheters and vegetations, vegetation weights, and number of bacteria per vegetation. Solid bars represent 1 C261 and open bars represent JL113. Vertical lines on columns in the characterization of vegetation graphs indicate SEM. Each group contained at least six animals. 
amined by Southern hybridization as previously described. Both isolates contained one copy of Tn916 with the same banding pattern; however, the banding pattern was different from that of JL1 13 (a non-animal passed strain). The different pattern suggests that $\mathrm{Tn} 916$ moved from the original location and the isolates reverted to the parental phenotype with the ability to adhere and cause IE.

To determine whether the differences observed between JL113 and the parent might be due to the presence of Tn916 insertion or the Tc resistance, another Tn916 recipient, JL211, was used in the in vitro adherence assay and the animal model. Fig. 5 shows the adherence results, obtained for the control strain JL211 compared with strains 1C261 and JL113. When the JL211 transconjugant was injected into rats at an inoculum of $10^{6} \mathrm{CFU}$, no differences were detected in the ability of JL211 to cause infections when compared with the parental organism 1C261 (Fig. 5). Significant differences were apparent between JL211 and the mutant JL113 when comparing infection rates for catheters ( 80 and $20 \%$, respectively) and vegetations ( $100 \%$ vs. 0 ). Likewise, in comparison to JL113 the vegetations were larger from rats infected with the JL211 strain ( $P$ $<0.011)$ and the numbers of bacteria recovered from infected vegetations were greater $(P<0.001)$. These data demonstrate that neither insertion of $\operatorname{Tn} 916$ into a silent location nor growth and maintenance of the transconjugants on Tc were responsible for the diminished virulence demonstrated by JL113.

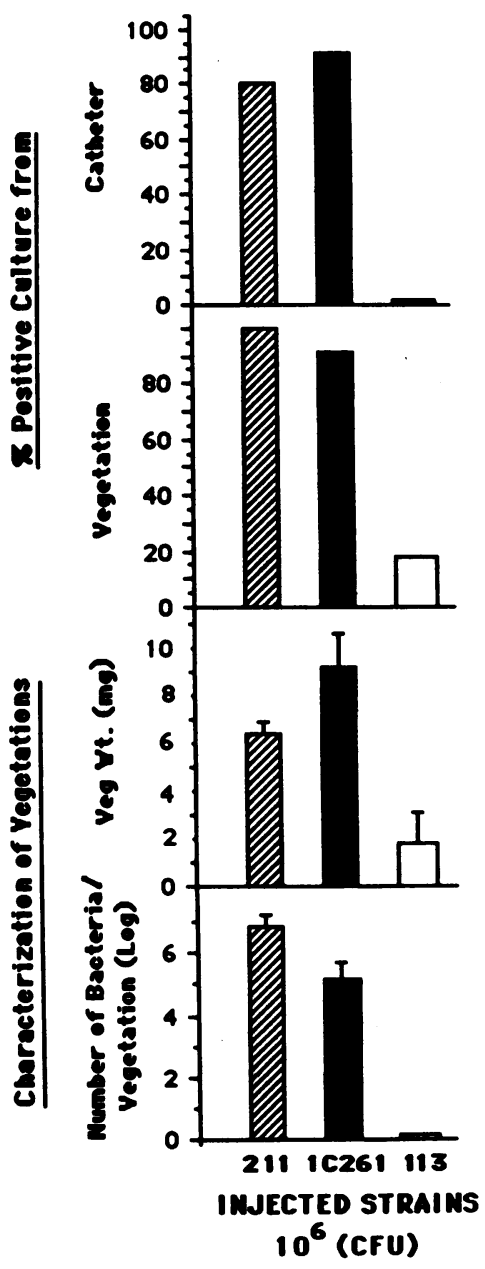

Figure 5. Comparison of virulence of JL211, 1C261, and $\mathrm{JL} 113$ at $10^{6} \mathrm{CFU} / \mathrm{ml}$ in the rat animal model of endocarditis. The parameters of virulence comparisons include infection rates of resected catheters and vegetations, vegetation weights, and the number of viable bacteria per vegetation. Hatched bars represent JL211, the transconjugant, solid bars represent $1 C 261$, the parent, and open bars represent the mutant, JL113. Each group contained at least six animals.
Excision of Tn916 from JL113. Previous investigators have shown that $\mathrm{Tn} 916$ excises from chromosomes in the absence of $\operatorname{Tc}(10,11)$. Spontaneous excision of $\operatorname{Tn} 916$ can occur either as a precise event that restores the parental phenotype or as an imprecise event that maintains the mutant phenotype (11). Therefore, JL113 was grown without Tc and plated onto SBA, and individual colonies were screened for the loss of Tc resistance. Screening produced two strains, JLR-15 and JLR-19, which were Tc sensitive. These two strains were screened for their ability to bind to Fn as previously described. We found that JLR-15 had regained the ability to bind to Fn, while JLR-19 retained the mutant phenotype of JL113 (data not shown).

Southern hybridization demonstrated that Tn916 was lost from both JLR-15 and JLR-19. The pAM120 probe for Tn916 reacted with JL113 but not with JLR-15 or JLR-19 (Fig. 3, lanes $B, D$, and $E$, respectively). In addition, both JLR-15 and JLR-19 retained the parental phenotypic marker of Sm resistance.

Once the excision of Tn916 was confirmed and the adherence phenotypes were characterized, these isolates were then tested for their virulence properties in the animal endocarditis model. At two different inocula the virulence of JLR-15 was similar to the virulence of the parent strain, 1C261 (Fig. 6). In contrast, JLR-19 was avirulent at both inocula (Fig. 6). Even with the highest inocula $\left(10^{8} \mathrm{CFU}\right), \mathrm{JLR}-19$ was significantly less virulent than JLR-15, as reflected by the vegetation weight and the number of viable bacteria per vegetation $(P<0.053$ and $P<0.001$, respectively). These data suggest that the original insert in JL113 was responsible for both the loss of Fn binding and the decreased virulence of this isolate.

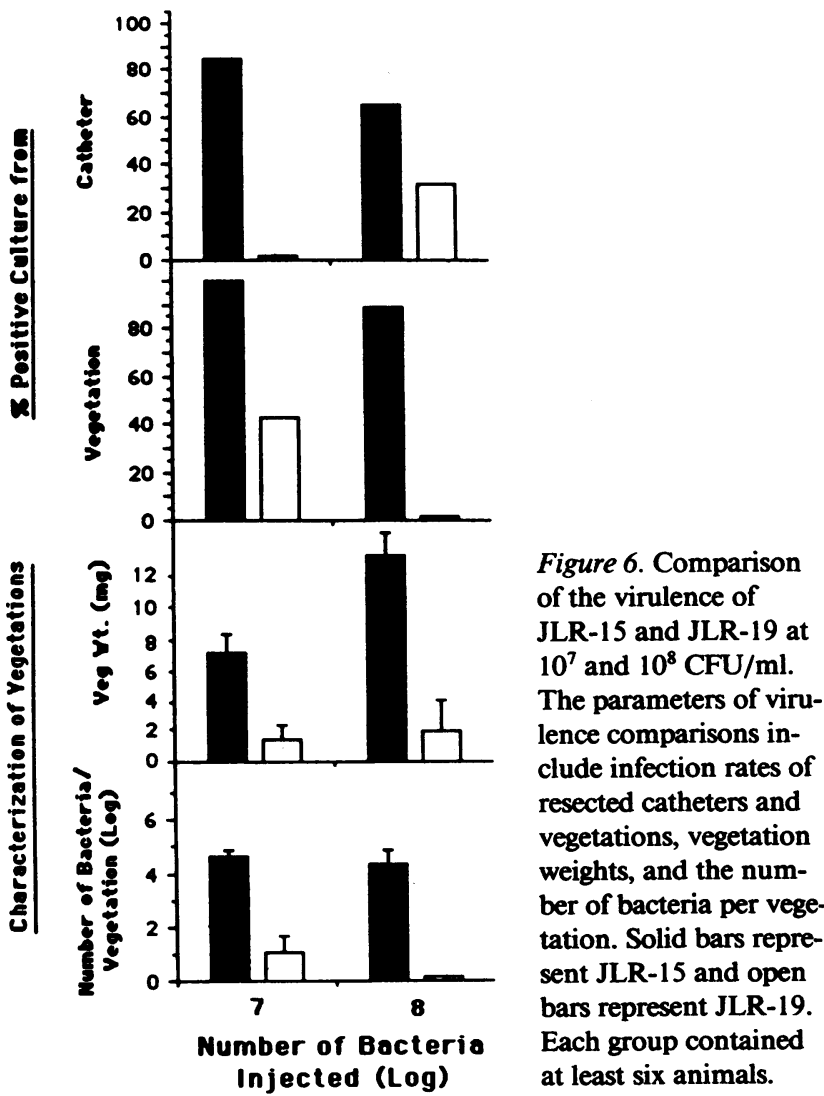




\section{Discussion}

Adherence of bacterial pathogens to host tissues is considered an early, critical step in the infectious process $(23,24)$. The studies presented herein suggest that $S$. sanguis must interact with Fn immobilized on the damaged endocardial surface to produce IE in this animal model. Previous work from our laboratory (7) showed that this strain of $S$. sanguis could bind to immobilized Fn in the presence of soluble Fn and suggested that $S$. sanguis might be able to utilize this conformationally sensitive receptor to adhere to immobilized Fn in the presence of whole blood (7). This observation prompted the present studies, which were designed to determine if mutants with diminished binding to Fn also caused less disease in the animal model of endocarditis. It is clear from our results that JL113 is less pathogenic than either the parent (1C261) or the revertant (JL-15).

Prior damage to the endocardium predisposes patients to IE $(25,26)$. This observation suggests that molecules either exposed by trauma or deposited at the site of trauma could function as specific receptors for the adherence of bacteremic pathogens that are responsible for IE. Fn is present both in the extracellular matrix and in the thrombi that form at the site of intravascular trauma $(27,28)$. Thus, $F n$ is in the proper location to function as a bacterial receptor. Fn is also implicated as a tissue receptor for such diverse organisms as Staphylococcus aureus $(29,30)$, Streptococcus pyogenes $(13,31)$, Treponema pallidum (32), and Trypanosoma cruzi (33). The mechanisms of binding appear to be unique in each of these cases involving unrelated bacterial molecules that bind to unique domains on the Fn molecule (34).

Recent studies reported by Kuypers and Proctor support the hypothesis that Fn functions as an important adherence determinant for IE (35). In these studies, the authors reported that a mutant of Staphylococcus aureus bound less Fn than the parental organism. Using an animal model similar to the one used in our studies they were able to show that the mutants adhered less avidly to the left (catheter damaged) side of the heart than did the parent strain. The mutation present in the nonbinding strain could be cotransformed with Tn916 into the parent. These data, when combined with those of the present study, strongly suggest that Fn plays a critical role in promoting the adherence of these two frequent pathogens to traumatized endocardial tissues and the production of IE.

Vercellotti et al. demonstrated that certain gram-positive cocci (including $S$. aureus and $S$. sanguis) that bind to Fncoated surfaces also adhere to endothelial cell surfaces (36). These same gram-positive bacteria commonly cause IE. In contrast, gram-negative bacteria like E. coli, Klebsiella pneumoniae, and Enterobacter cloacae, which rarely cause IE, were demonstrated to bind poorly to Fn-coated surfaces and endothelial cells (36). Vercellotti suggested a correlation between bacterial adherence to Fn-coated surfaces and to endothelial cells, indicating that Fn might be important for bacterial adherence to damaged endothelial surfaces (36). Scheld et al. made a similar observation that the propensity of an organism to cause IE was closely related to the ability to bind to Fn (37). For example, endocarditis-producing strains like $S$. aureus and $S$. sanguis bound significantly more Fn than did $E$. coli and Pseudomonas aeruginosa, which rarely produce IE except in intravenous drug addicts (28). Durack and Beeson also determined that certain gram-negative bacteria, which frequently cause bacteremia, rarely produce IE, while gram-positive cocci that cause bacteremia commonly produce IE $(38,39)$. Together, these data support the suggestion that Fn mediates the adherence of certain endocarditis-producing strains like $S$. sanguis to damaged valvular tissue.

While these studies highlight the importance of specific tissue receptors, additional work is needed to identify the specific bacterial adhesins involved in these interactions. Several distinct mechanisms could produce mutants with phenotypically altered Fn-binding characteristics. Mutations that alter the transport of surface molecules, affect the regulation of Fnbinding molecules, and alter the expression of capsular antigens or other factors (such as hydrophobicity) could all conceivably produce similar phenotypes. At the present time we have not determined that the transposon has disrupted a gene that is directly responsible for Fn binding. More detailed studies on the proposed Fn adhesin of $S$. sanguis are needed to understand the molecular events involved in the reduced binding to Fn and to determine their relationship to the reduced virulence of this mutant.

\section{Acknowledgments}

The authors thank Joyce Sheffield for excellent secretarial assistance in preparing this manuscript and Suzie Ferranbach for excellent technical assistance. In addition, we thank G. D. Christensen, H. D. Gresham, and D. L. Hasty for their critical reviews of this manuscript and for their thoughtful discussions.

These studies were supported by a research grant from the Department of Veterans Affairs and U.S. Public Health Service grant DE-07218 from the National Institutes of Health. Dr. Simpson is an Associate Career Scientist with the Department of Veterans Affairs.

\section{References}

1. Baddour, L. M., G. D. Christensen, J. H. Lowrance, and W. A. Simpson. 1989. A review of pathogenesis gleaned from animal models of experimental endocarditis. Rev. Infect. Dis. 11:452-463.

2. Baddour, L. M. 1988. Twelve-year review of recurrent nativevalve infectious endocarditis: a disease of the modern antibiotic era. Rev. Infect. Dis. 10:1163-1170.

3. Robert, R. B., A. G. Krieger, N. L. Schiller, and K. C. Gross. 1979. Viridans streptococci endocarditis: the role of various species, including pyridoxal-dependent streptococci. Rev. Infect. Dis. 1:955966.

4. Hamill, R. J. 1987. Role of fibronectin in infective endocarditis. Rev. Infect. Dis. 4(Suppl. 9):360-371.

5. Scheld, W. M., and M. A. Sande. 1989. Endocarditis and intervascular infections. In Principles and Practice of Infectious Diseases. G. L. Mandel, R. G. Douglas, and J. E. Bennett, editors. John Wiley \& Sons, Inc., New York. 670-706.

6. Herzberg, M. C., K. L. Brintzenhofe, and C. C. Clawson. 1983. Aggregation of human platelets and adhesion of Streptococcus sanguis. Infect. Immun. 39:1457-1469.

7. Lowrance, J. H., D. L. Hasty, and W. A. Simpson. 1988. Adherence of Streptococcus sanguis to conformationally specific determinants in fibronectin. Infect. Immun. 56:2279-2285.

8. Switalski, L. M., H. Murchison, R. Timpl, R. Curtiss III, and M. Hook. 1987. Binding of laminin to oral and endocarditis strains of viridans streptococci. Infect. Immun. 169:1095-1101.

9. Vercellotti, G. M., J. B. McCarthy, P. Lindholm, P. K. Peterson, H. S. Jacob, and L. T. Furcht. 1985. Extracellular matrix proteins (fibronectin, laminin, and type IV collagen) bind and aggregate bacteria. Am. J. Pathol. 120:13-21. 
10. Gawron-Burke, C., and D. B. Clewell. 1984. Regeneration of insertionally inactivated streptococcal DNA fragments after excision of transposon Tn916 in Escherichia coli: strategy for targeting and cloning of genes from gram positive bacteria. J. Bacteriol. 159:214221.

11. Clewell, D. B., and C. Gawron-Burke. 1986. Conjugative transposons and the dissemination of antibiotic resistance in streptococci. Annu. Rev. Microbiol. 40:635-659.

12. Engvall, E., and E. Ruoslahti. 1977. Binding of soluble form of fibroblast surface protein, fibronectin, to collagen. J. Cancer Res. 10:1-5.

13. Courtney, H. S., I. Ofek, W. A. Simpson, D. L. Hasty, and E. H. Beachey. 1986. Binding of Streptococcus pyogenes to soluble and insoluble fibronectin. Infect. Immun. 53:454-459.

14. Hasty, D. L., H. S. Courtney, W. A. Simpson, J. A. Mcdonald, and E. H. Beachey. 1986. Immunochemical and ultrastructural mapping of the gelatin-binding and cell-binding regions of human plasma fibronectin with monoclonal antibodies. J. Cell Sci. 81:125-141.

15. Schifferli, D. M., S. N. Abraham, and E. H. Beachey. 1987. Use of monoclonal antibodies to probe subunit- and polymer-specific epitopes of 987P fimbriae of Escherichia coli. Infect. Immun. 55:923-930.

16. Baddour, L. M., G. D. Christensen, M. G. Hester, and A. L. Bisno. 1984. Production of experimental endocarditis by coagulasenegative staphylococci: variability in species virulence. J. Infect. Dis. 150:721-727.

17. Santoro, J., and M. E. Levison. 1978. Rat model of experimental endocarditis. Infect. Immun. 19:915-918.

18. Maniatis, T., E. F. Fritsch, and J. Sambrook. 1982. Molecular Cloning: A Laboratory Manual. Cold Spring Harbor Laboratory, Cold Spring Harbor, NY. 545 pp.

19. Southern, E. M. 1975. Detection of specific sequences among DNA fragments separated by gel electrophoresis. J. Mol. Biol. 98:503-517.

20. Wahl, G. M., M. Stern, and G. R. Start. 1979. Efficient transfer of large DNA fragments from agarose gels to diazobenzyloxymethyl paper and rapid hybridization by using dextran sulfate. Proc. Natl. Acad. Sci. USA. 76:3683-3687.

21. Henrikson, S. D., and J. Henrichsen. 1975. Twitching motility and possession of polar fimbriae in spreading Streptococcus sanguis isolates from the human throat. Acta Pathol. Microbiol. Scand. Sect. B Microbiol. 83:133-140.

22. Facklam, R. R. 1977. Physiological differentiation of viridans streptococci. J. Clin. Microbiol. 5:184-201.

23. Beachey, E. H. 1981. Bacterial adherence: adhesin-receptor interactions mediating the attachment of bacteria to mucosal surfaces. J. Infect. Dis. 143:325-345.

24. Baddour, L. M., G. D. Christensen, W. A. Simpson, and E. H. Beachey. 1989. Microbial adherence in infection. In Principles and
Practice of Infectious Diseases. G. L. Mandell, R. G. Douglas, and J. E. Benett, editors. John Wiley \& Sons, Inc., New York. 9-25.

25. Scheld, W. M. 1984. Pathogenesis and pathophysiology of infective endocarditis. In Endocarditis. M. A. Sande, D. Kaye, and R. K. Root, editors. Churchill-Livingstone, Inc., New York. 1-32.

26. Sullam, P. M., T. A. Durack, and M. A. Sande. 1985. Pathogenesis of endocarditis. Am. J. Med. 78:110-115.

27. Kerenyi, T. V. B., J. Rauterberg, H.-G. Fromme, H. Jellinek, and W. H. Hauss. 1985. Connective tissue proteins on the injured endothelium of the rat aorta. Exp. Mol. Pathol. 43:151-161.

28. Scheld, W. M., R. W. Strunk, G. Balian, and R. A. Calerone. 1985. Microbial adhesion to fibronectin in vitro correlates with production of endocarditis in rabbits (42205). Proc. Soc. Exp. Biol. Med. 180:474-482.

29. Kuusela, P. 1978. Fibronectin binds to Staphylococcus aureus. Nature (Lond.). 267:680-685.

30. Mosher, D. F., and R. A. Proctor. 1980. Binding and factor $\mathrm{XIII}_{\mathrm{a}}$-mediated cross-linking of a 27 kilodalton fragment of fibronectin to Staphylococcus aureus. Science (Wash. DC). 209:927-929.

31. Switalkski, L. M., A. Ljungh, C. Ryden, K. Rubin, M. Hook, and T. Wadstrom. 1982. Binding of fibronectin to the surface of groups A, C, and G streptococci. Eur. J. Clin. Microbiol. 1:381-387.

32. Thomas, D. D., J. B. Baseman, and J. F. Alderette. 1985. Fibronectin mediates Treponema pallidum cytadherence through recognition of fibronectin cell-binding domain. J. Exp. Med. 161:514525.

33. Ouaissi, M. A., J. Cornette, and A. Capron. 1985. Trypanosoma cruzi infection inhibited by peptides modeled from a fibronectin cell attachment domain. Eur. J. Immunol. 15:1096-1101.

34. Hasty, D. L., E. H. Beachey, H. S. Courtney, and W. A. Simpson. 1989. Interactions between fibronectin and bacteria. In Fibronectin in Health and Disease. S. Carsons, editor. CRC Press, Inc., Boca Raton, FL. 89-127.

35. Kuypers, J. M., and R. A. Proctor. 1989. Reduced adherence to traumatized rat heart valves by a low-fibronectin-binding mutant of Staphylococcus aureus. Infect. Immun. 57:2306-2312.

36. Vercellotti, G. M., D. Lussenhop, P. K. Peterson, L. T. Furcht, J. B. McCarthy, H. S. Jacob, and C. F. Moldow. 1984. Bacterial adherence to fibronectin and endothelial cells: a possible mechanism for bacterial tissue tropism. J. Lab. Clin. Med. 103:34-43.

37. Scheld, W. M., J. A. Valone, and M. A. Sande. 1978. Bacterial adherence in the pathogenesis of endocarditis: interaction of the bacterial dextran, platelets, and fibrin. J. Clin. Invest. 61:1394-1404.

38. Durack, D. T., and P. B. Beeson. 1972. Experimental endocarditis. I. Colonization of a sterile vegetation. Br. J. Exp. Pathol. 53:4449.

39. Durack, D. T., P. B. Beeson, and R. G. Petersdorf. 1973. Experimental bacterial endocarditis III: production and progress of the disease in rabbits. Br. J. Exp. Pathol. 54:142-151. 